\title{
Perancangan Sistem Informasi Rental Alat Gunung Adventure Cloting di Mangun Jaya
}

\author{
Sinta Rukiastiandari ${ }^{1}$, Hamdun Sulaiman ${ }^{2}$, Muhamad Abdul Ghani ${ }^{3}$ \\ 1,2,3 Universitas Bina Sarana Informatika \\ e-mail: ${ }^{1}$ sinta.sru@bsi.ac.id, ${ }^{2}$ hamdun.hsl@bsi.ac.id, ${ }^{3}$ muhamad.mag@bsi.ac.id
}

\begin{tabular}{ccc}
\hline Diterima & Direvisi & Disetujui \\
$03-05-2021$ & $19-05-2021$ & $06-09-2021$ \\
\hline
\end{tabular}

\begin{abstract}
Abstrak - Adventure clothing merupakan salah satu tempat usaha yang bergerak di bidang jasa penyewaan alat gunung yang berlokasi di mangun jaya. Toko ini menyediakan alat alat gunung yang disewakan yaitu: tenda, tas carrier, sepatu trekking, sleping bag, head lamp, nesting, kompor, gas portable, matras, trecking pole, geiter. Permasalahan yang terjadi pada adventure clothing yaitu proses transaksi penyewaan alat gunung di adventure clothing masih menggunakan sistem konvesional atau masih manual yaitu masih menggunakan media kertas untuk setiap pencatatan dalam setiap sitemnya, baik dalam sistem mengolah data barang penyewaan, pengembalian, dan pembayaran masih di lakukan dengan mencatat di kertas penyewaan, sehingga menyebabkan proses pelayanan menjadi sangat lama dan kemungkinan bukti penyewaan bisa terjadi hilang/rusak. Untuk itu penulis membuat sistem informasi penyewaan alat gunung adventure cloting di mangun jaya, dengan adanya sistem ini diharapkan dapat membantu sistem penyewaan alat gunung menjadi lebih mudah. Metode perangkat lunak yang digunakan adalah Waterfall yang terbagi menjadi lima yaitu (Analisa kebutuhan perangkat lunak, Design, Pembuatan kode program, Pengujian dan Pendukung atau Pemeliharaan).dan menggambarkan perancangan database menggunakan ERD dan LRS.teknik pengumpulan data yang digunakan yaitu metode observarsi,wawancara dan studi pustaka. Dengan mengimplementasikan menggunakan prototype menggunakan Neatbeans sehingga membantu proses penyewaan agar menjadi efektif dan efisien.
\end{abstract}

Kata Kunci: Sistem Informasi, Penyewaan Alat Gunung, Adventure clothing, Waterfal, Neatbeans

Abstract - Adventure clothing is a place of business engaged in mountain equipment rental services located in Mangun Jaya. This shop provides rental mountain equipment, namely: tents, carrier bags, trekking shoes, sleeping bags, head lamps, nesting, stoves, portable gas, mattresses, trekking poles, geiters. The problem that occurs in adventure clothing is that the transaction process for leasing mountain equipment in adventure clothing still uses the conventional system or is still manual, which is still using paper media for each record in each system, both in the system for processing data on rental goods, returns, and payments are still done with record on the rental paper, causing the service process to be very long and the possibility of the rental evidence being lost/damaged. For this reason, the author makes an information system for mountain equipment rental adventure cloting in Mangun Jaya, with this system it is expected to help the mountain equipment rental system become easier The software method used is Waterfall which is divided into five, namely (Analysis of software requirements, Design, Program code creation, Testing and Support or Maintenance). And describes database design using ERD and LRS. Data collection techniques used are observation, interview methods. and literature study. By implementing using a prototype using Neatbeans so that it helps the rental process to be effective and efficient.

Keywords: Information System, Mountain Equipment Rental, Adventure clothing, Waterfal Method, Neatbeans

\section{PENDAHULUAN}

Kemajuan teknologi saat ini yang sangat cepat dan menjadi kebutuhan utama di berbagai bidang usaha, "Langkah utama dalam kegiatan bisnis untuk bersaing dengan para pesaingnya adalah menggunakan komputer sebagai sarana untuk meningkatkan efektifitas kerja."(Nugraha \& Arnie, 2017)
Internet juga menjadi point penting saat ini karena jaringan yang mudah diakses dan cepat. $E$ Commerce di artikan sebagai proses berbisnis menggunakan teknologi elektronik yang menghubungkan antara perusahaan, konsumen, dan masyarakat dalam bentuk transaksi elektronik dan pertukaran atau penjualan barang, servis, maupun informasi secara elektornik (Sumarni et al., 2019). Salah satu contohnya adventure clothing. 
Adventure clothing merupakan salah satu tempat usaha yang bergerak di bidang jasa penyewaan alat gunung yang berlokasi di mangun jaya. Toko ini menyediakan alat alat gunung yang disewakan yaitu: tenda, tas carrier, sepatu trekking, sleping bag, head lamp, nesting, kompor, gas portable, matras, trecking pole, geiter. Cara penyewaanya yaitu dengan mendatangi langsung ke toko untuk memboking alat yang ingin disewa, sebelum melakukan peminjaman di anjurkan meminjam diantara 3-4 hari dengan tujuan supaya tidak kehabisan alat yang disewa, dan penjaga toko langsung mencatat data di nota sebagai bukti transaksi penyewaan yang terdiri dari nama \& banyak alat, harga sewa perhari, lama sewa, total harga yang disewakan.

Persyaratan pokok saat penyewaan yaitu wajib meninggalkan id asli seperti KTP/SIM, sekaligus membayar uang jaminan sebesar 50\% sisa pembayaran setelah barang di antar dan diterima oleh penyewa, pembatalan sepihak dari si penyewa maka uang jaminan hangus, tanda tangan persetujuan saat menyewa oleh penjaga toko dan penyewa. yang jika terjadi kerusakan wajib denda sebesar biaya perbaikan, sedangkan jika terjadi kehilangan barang yang di sewa maka penyewa wajib mengganti berupa barang sesuai jenis barang yang sama/berupa uang, keterlambatan pengembalian barang yang disewa denda 1,5 lipat biaya sewa perhari.

Permasalahan yang terjadi pada adventure clothing yaitu proses transaksi penyewaan disana masih sangat manual yaitu dengan menggunakan media kertas dalam arti mengolah data barang penyewaan, pengembalian, dan pembayaran masih di lakukan dengan mencatat di kertas penyewaan. sehingga menyebabkan proses pelayanan menjadi sangat lama dan kemungkinan bukti penyewaan bisa terjadi hilang/rusak.

Dari penelitian ini akan merancang sistem informasi penyewaan adventure clothing agar dapat memperbaiki kekurangan yang ada seperti pencatatan identitas penyewa yang masih menggunakan media kertas menjadi sistem penyewaan yang berbasis online contohmya dalam hal pengisian formulir peminjaman dan memeriksa ketersedian fasilitas yang di butuhkan saat itu juga, disisi lain data peminjaman fasilitas sudah tersimpan di database dan siap untuk di olah sesuai kebutuhan.

\section{METODE PENELITIAN}

Metode perancangan sistem informasi persewaan alat gunung dalam penelitian ini menggunakan metode waterfall yang terdiri dari 5 Tahap yang terdiri dari:

1. Analisis Kebutuhan

Penulis melakukan analisa untuk mengumpulkan informasi yang akan di butuhkan dalam penyewaan. Admin dan User membutuhkan login secara penuh, untuk dapat mengola data penyewaan di mangun jaya.

2. Desain

Dari analisa di atas dibuatlah diagram ERD, LRS, dan UML serta database dengan tabel user, tabel transaksi, tabel laporan. Dengan interface yang di butuhkan yaitu form login, form user, form transaksi, cetak laporan, dan form logout. Dengan menggunakan bahasa pemograman java dan database SQL.

3. Pengkodean

Tahapan ini membuat pengkodean sesuai dengan desain perangkat lunak menggunakan Netbeans IDE

\section{Pengujian}

Pada tahap ini, pengujian ini menggunakan bahasa pemograman java, dan pengujian secara fungsional dilakukan dengan black box testing, dimana kita akan mengetahui apakah program kita yang dibuat berjalan sesuai apa yang kita inginkan. Dan jika sistem yang dibutuhkan sudah berjalan dengan benar dan siap untuk dipakai oleh user.

5. Maintenance

Tahap ini dengan membuat rancangan prototipe untuk memudahkan penyewaan agar lebih sistematis ketimbang sistem berjalan saat ini

\section{HASIL DAN PEMBAHASAN}

Dari pembahsan di atas, maka diambil berdasarkan permasalahan yang diangkat dalam penelitian ini dirancanglah sebuah system terkomputerisasi sebagai berikut :

1. Analisa Kebutuhan

Penjagatoko (Admin) \& User membutuhkan login secara penuh, untuk dapat mengola data penyewaan di mangun jaya.

\section{A. Kebutuhan pengguna}

Dalam aplikasi penyewaan terdapat dua pengguna yang dapat saling berinteraksi dalam lingkungan sistem, yaitu: Bagian Admin, dan Penyewa. Kedua pengguna tersebut memiliki karakteristik interaksi dengan sistem yang berbedabeda dan memiliki kebutuhan informasi yang berbeda-beda, seperti berikut :

A1. Kebutuhan Penjaga toko

a. Dapat melakukan Login

b. Dapat Melihat, Menambah, Mengahapus, Mengubah data user yang sudah melakukan transaksi penyewaan

c. Dapat Melihat, Menambah, Menghapus, Mengubah data alat yang tersedia.

d. Dapat melihat data pengembalian

e. Dapat mencetak laporan

f. Dapat melakukan logout 
A2. Kebutuhan User (Penyewa)
a. Dapat melakukan Login
b. Dapat Menambah, Menghapus, Mengubah data transaksi penyewaan
c. Dapat Melihat data barang yang tersedia.
d. Dapat cetak bukti transaksi
e. Menginput data pengembalian \& cetak bukti pengembalian.
f. Dapat melakukan logout

B. Kebutuhan Sistem

1. Pengguna harus melakukan login terlebih dahulu untuk dapat mengakses aplikasi ini dengan memasukan username dan passwrod agar privasi masing-masing pengguna tetap terjaga keamananya.

2. Pengguna harus melakukan logout setelah selesai setelah menggunakan aplikasi.

2. Rancangan Use Case

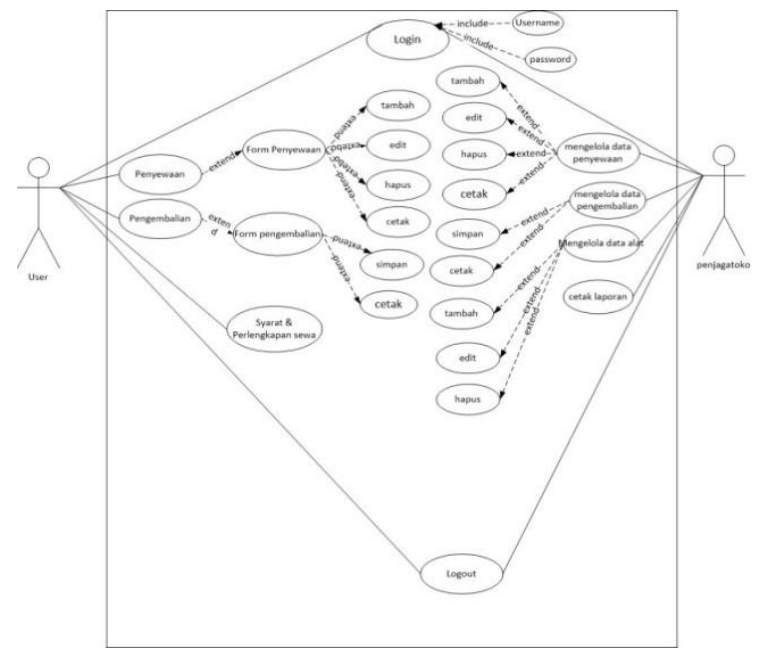

Sumber : Hasil Penelitian

Gambar 1. Use case Diagram

3. Rancangan Activity Diagram

a. Activity Diagram Login

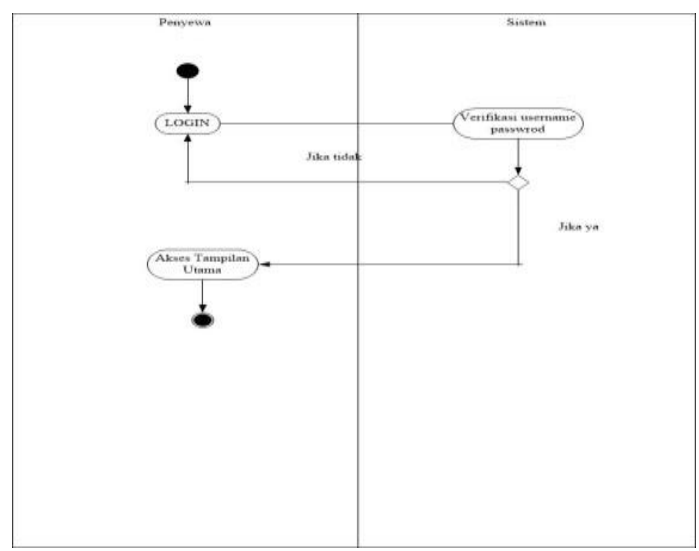

Sumber : Hasil Penelitian

Gambar 2. Activity Diagram Login b. Activity Diagram Penyewaan alat gunung

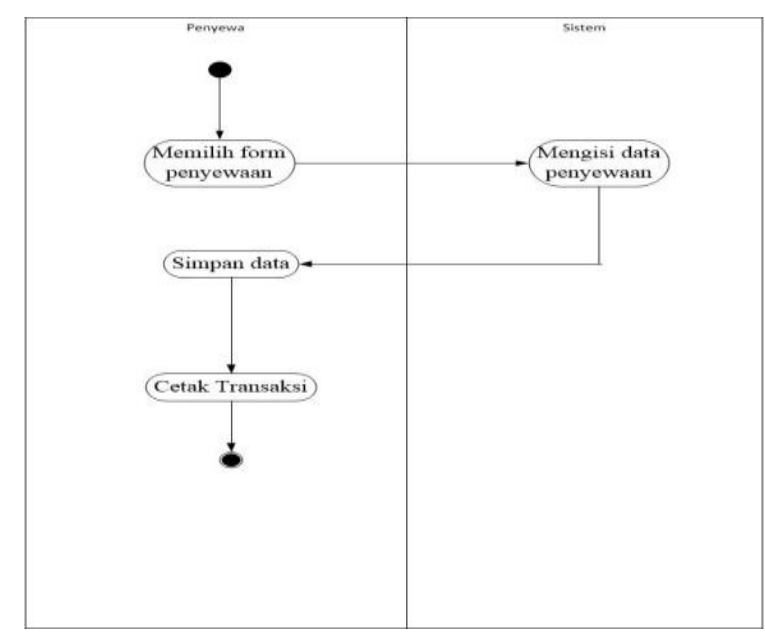

Sumber : Hasil Penelitian

Gambar 3. Activity Diagram Penyewaan alat gunung

c. Acivity Diagram Pengembalian alat gunung

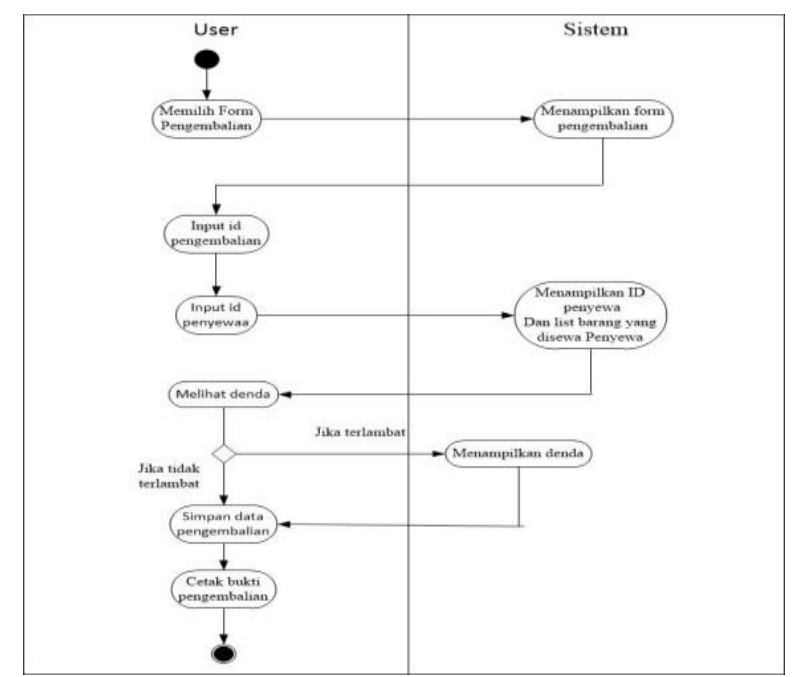

Sumber : Hasil Penelitian

Gambar 4. Activity Diagram Pengembalian alat gunung

4. Rancangan Prototype

a. Tampilan Login

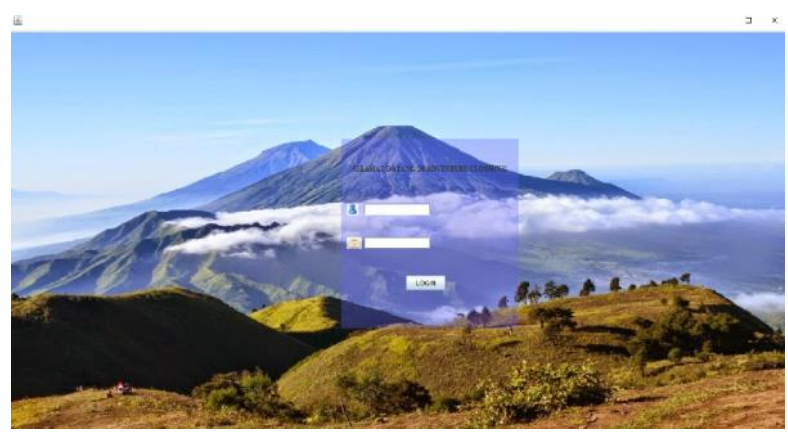

Sumber : Hasil Penelitian

Gambar 5. Tampilan Login 
b. Tampilan Halaman Utama

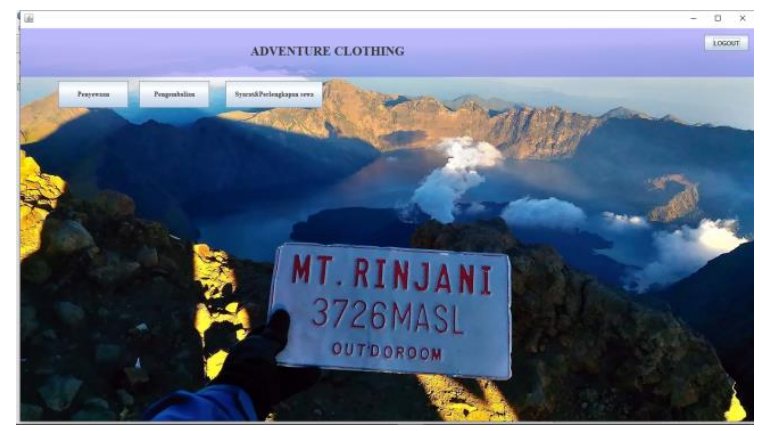

Sumber : Hasil Penelitian

Gambar 6. Tampilan Halaman Utama

c. Tampilan Data Penyewaan

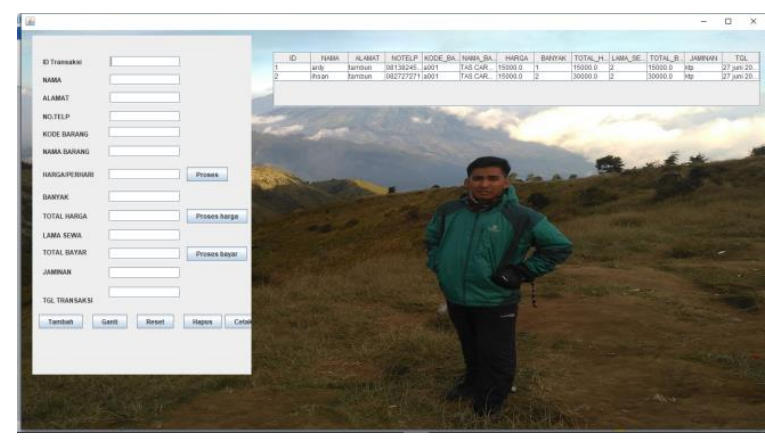

Sumber : Hasil Penelitian

Gambar 7. Tampilan Data Penyewaan

d. Tampilan Syarat dan Perlengkapan

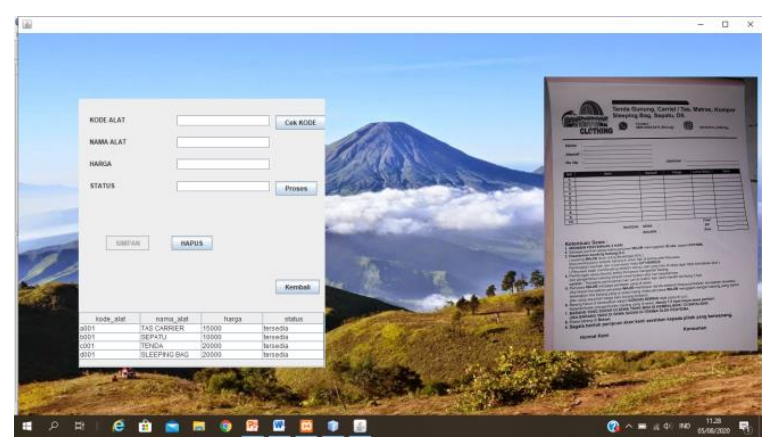

Sumber : Hasil Penelitian

Gambar 8. Tampilan Data Penyewaan

e. Tampilan Pengembalian

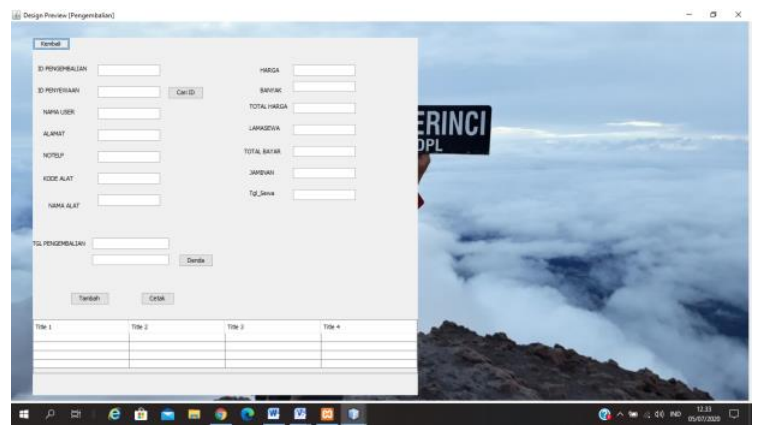

Sumber : Hasil Penelitian

Gambar 9. Tampilan Pengembalian f. Tampilan Kwitansi Pengembalian

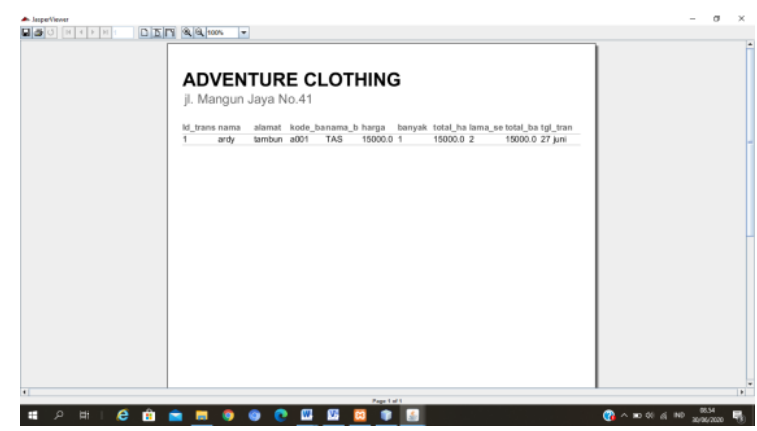

Sumber : Hasil Penelitian

Gambar 10. Tampilan Kwitansi Pengembalian

g. Tampilan Login Penjaga Toko

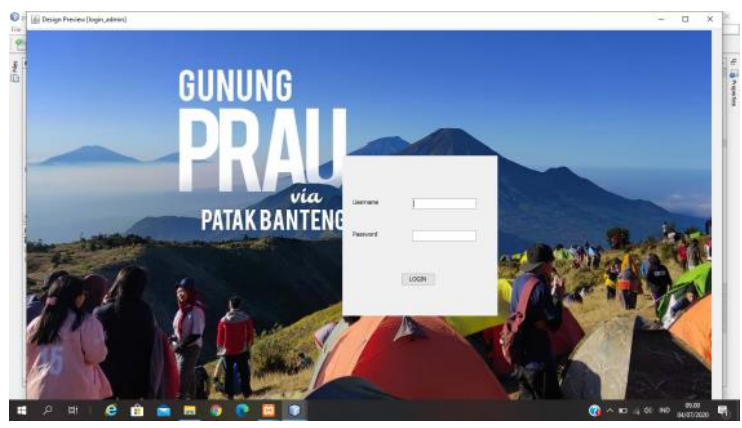

Sumber : Hasil Penelitian

Gambar 11. Tampilan Login Penjaga Toko

h. Tampilan Halaman Utama Penjaga Toko

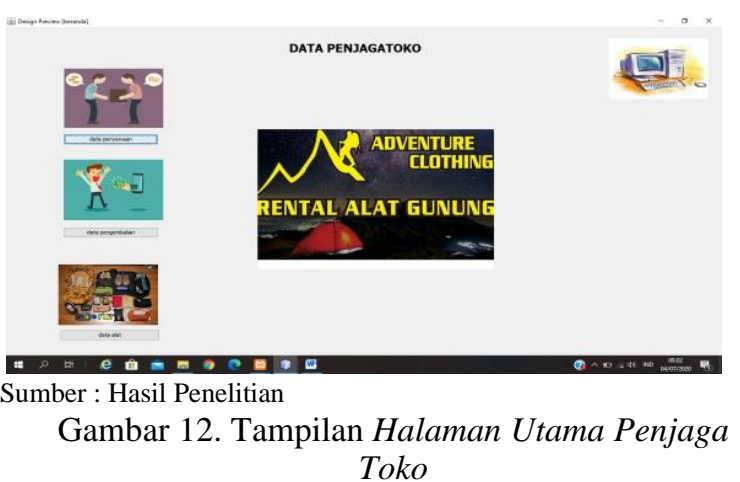

i. Tampilan Penyewaan Penjagatoko

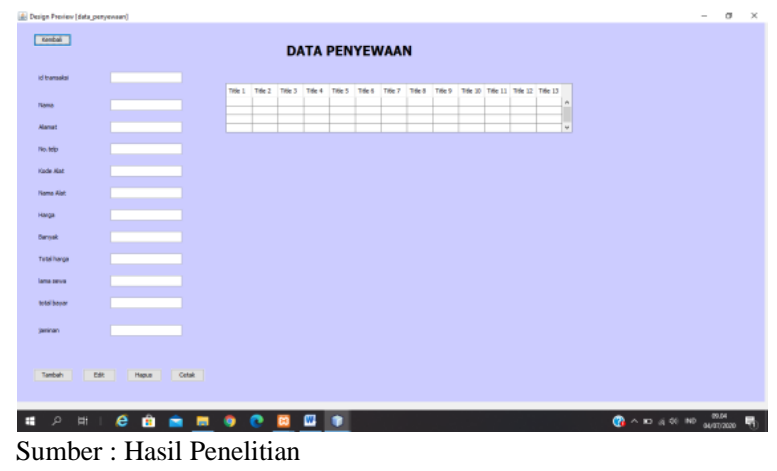

Gambar 13. Tampilan Penyewaan Penjagatoko 
j. Tampilan Data Alat Penjagatoko

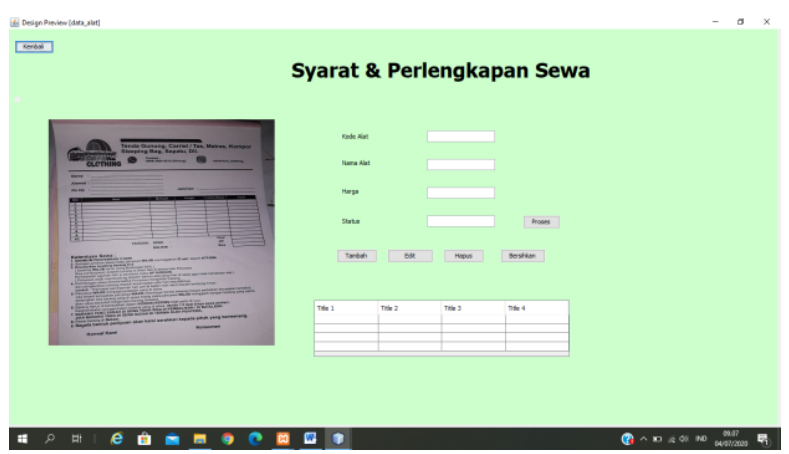

Sumber : Hasil Penelitian

Gambar 14. Tampilan Data Alat Penjagatoko

k. Tampilan Data Pengembalian Penjagatoko

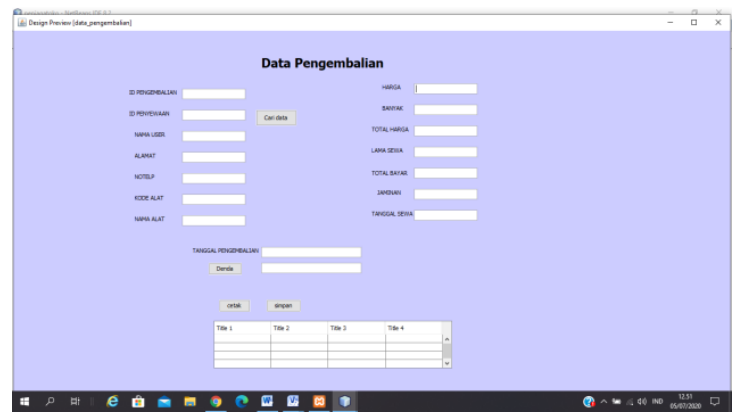

Sumber : Hasil Penelitian

Gambar 15. Tampilan Data Pengembalian Penjagatoko

\section{KESIMPULAN}

Dari hasil pembahasan mengenai Sistem Informasi Rental Alat Gunung Adventure Cloting maka dengan adanya sistem ini proses penyewaan alat gunung di Adventure Cloting dapat lebih mudah untuk sistem penyewaan alat gunung tersebut. sehingga membantu proses penyewaan agar menjadi efektif dan efisien.

\section{REFERENSI}

Abdulloh, R. (2018). 7 in 1 Pemograman Web untuk Pemula (R. Abdulloh (ed.)). PT Elex Media Komputindo.

Astuti, P. (2018). Perancangan Sistem Informasi Penjualan Sepatu Menggunakan Microsoft Visual Basic 6.0. Indonesian Journal on Software Engineering, 4, 73-78.

Astuti, S. T., \& Rapiyanta, P. T. (2018). Perancangan Sistem Informasi Berbasis Website Pada Persewaan Alat Camping. Program Studi Sistem Informasi, Universitas
Bina Sarana Informatika, 10, 112-116.

Batubara, H. H. (2018). Pemodelan berbasis web dengan moodle versi 3.4. DEEPUBLISH.

Ermatita. (2016). ANALISIS DAN PERANCANGAN SISTEM INFORMASI PERPUSTAKAAN. Jurusan Sistem Informasi, Fakultas Ilmu Komputer Universitas Sriwijaya, 8, 966-977.

Fauzi, A., Erniawati, \& H, A. S. (2019). SISTEM INFORMASI PEMESANAN KERTAS CONTINUOUS FORM PT. ERAJAYA MANDIRI PRATAMA JAKARTA. Jurnal Teknologi Informatika \& Komputer, 5, 123127.

Haqi, B. (2019). Aplikasi SPK pemilihan Dosen Terbaik Metode Simple Additive Weighting (SAW) dengan JAVA (A. H. Zein (ed.)). CV BUDI UTAMA.

Hutaean, J. (2015). KONSEP SISTEM INFORMASI (U. P. Hastanto (ed.)). CV BUDI UTAMA.

Indrajani. (2015). DATABASE Design. PT Elex Media Komputindo.

Mulyani, S. (2016). ANALISIS DAN PERANCANGAN SISTEM INFORMASI MANAJEMEN KEUANGAN DAERAH NOTASI PEMODELAN UNIFIED MODELING LANGUAGE(UML) (A. Zulvani (ed.)). Abdi Sistematika.

Musihudin, M., \& Oktafianto. (2016). Analisis dan Perancangan Sistem Informasi (A. Pramesta (ed.)). CV.ANDI OFFSET.

Nasutio, N., \& Hasan, A. (2017). Aplikasi Sistem Informasi Penyewaan Fasilitas Di Universitas Lancang Kuning Berbasis Online. Program Studi Teknik Informatika Fakultas Ilmu Komputer Universitas Lancang Kuning, 2, 198-204.

Novendri, M. S., Saputra, A., \& Firman, C. E. (2019). APLIKASI INVENTARIS BARANG PADA MTS NURUL ISLAM DUMAI MENGGUNAKAN PHP DAN MYSQL. LENTERA DUMAI, 10, 46-57.

Nugraha, A. S. H., \& Arnie, R. (2017). Sistem Informasi Penjualan Dan Penyewaan Peralatan Camping Berbasis Web Pada Oasis Camp. Program Studi Teknik Informatika, STMIK Banjarbaru, 13, 1741-1752.

Nugroho, A. (2017). Pemodelan Berorientasi Objek mengguakan C\# (Yeskha (ed.)). ANDI.

Sabarudin, S., \& Arif, S. (2019). PEMBANGUNAN SISTEM INFORMASI PENYEWAAN ALAT CAMPING BERBASIS WEB DI POTONG KOMPAS. Fakultas Ilmu Komputer Universitas Nasional PASIM, 10, 68-77.

Saputra, D., Purwaningtias, D., \& Irnmayanti, W. (2018). SISTEM PAKAR DIAGNOSA 
KERUSAKAN MESIN SEPEDA MOTOR MATIC BERBASIS

WEB MENGGUNAKAN CERTAINTY FACTOR. Jurnal.Umj.Ac.Id, 1-11.

Sumarni, T., Wahyuningsih, S., \& Roinah. (2019). JUAL BELI ONLINE (E-COMERCE) BERBASIS MEDIA SOSIAL DALAM SUDUT PANDANG EKONOMI SYARIAH.
Seminar Nasional Industri Dan Teknologi (SNIT), Politeknik Negeri Bengkalis, 25(2019: SNIT 2019), 226-235. 